\title{
Spontaneous Drainage of a Pancreatic Pseudocyst After Embolization of a Bleeding Pseudoaneurysm
}

\author{
M. T. Uiterwaal · E. H. Overbosch • \\ M. J. Bruno - R. W. M. van der Hulst
}

Published online: 17 September 2008

(c) The Author(s) 2008. This article is published with open access at Springerlink.com

Pancreatic pseudocyst formation occurs in approximately $20 \%$ to $40 \%$ of patients with a history of chronic pancreatitis. Most pseudocysts are asymptomatic; however, a wide range of clinical symptoms may occur [1-3]. Pseudocysts associated with chronic pancreatitis may resolve spontaneously, but exactly how often this occurs remains somewhat obscure, with reported incidence rates between $3 \%$ and $26 \%$ [1, 3, 4]. Several mechanisms may account for spontaneous resolution, including drainage into the gastrointestinal tract through the pancreatic duct as well as fistula formation [4-9]. We describe a case of spontaneous drainage of a large pancreatic pseudocyst into the stomach after embolization of a ruptured pseudoaneurysm.

\section{Case Report}

A 46-year-old woman presented to the emergency department with complaints of abdominal pain associated with

M. T. Uiterwaal ( ()

Department of Gastroenterology and Hepatology, VU University

Medical Centre, PO BOX 7057, 1007 MB Amsterdam,

The Netherlands

e-mail: uiterwaal@vumc.nl

E. H. Overbosch

Department of Radiology, Kennemer Gasthuis, Haarlem,

The Netherlands

\section{J. Bruno}

Department of Gastroenterology and Hepatology, University

Medical Center Rotterdam, Rotterdam, The Netherlands

R. W. M. van der Hulst

Department of Gastroenterology and Hepatology,

Kennemer Gasthuis, Haarlem, The Netherlands 1-day-old nausea and vomiting. She had a medical history of chronic alcoholic pancreatitis and alcoholic liver cirrhosis. The patient claimed abstinence from alcohol during the past month. On physical examination the patient was afebrile with normal vital signs. The abdomen was tender in the left upper quadrant. There were no signs of ascitic fluid. Laboratory tests showed a hemoglobin level of $15.5 \mathrm{~g} / \mathrm{dL}$ (normal range 12-16), normal white blood cell count, normal platelet count, and normal INR. Liver tests were normal. Serum amylase and lipase levels were slightly elevated. Abdominal computed axial tomography (CAT) showed features of chronic pancreatitis, cirrhotic liver, and a large pseudocyst approximately $10 \times 8 \mathrm{~cm}$ in size and originating from the tail of the pancreas, thus impressing the fundus of the stomach. It was concluded that the patient was having an episode of acute chronic pancreatitis complicated by a large pseudocyst. The patient was managed conservatively with intravenous fluid replacement, NPO status, and administration of analgesics.

On the third day of admission she suddenly became hemodynamic unstable. Laboratory test showed a hemoglobin decrease to $7.3 \mathrm{~g} / \mathrm{dL}$. Because there were no signs of an acute gastrointestinal bleeding, such as rectal blood loss or melena, bleeding from a pseudoaneurysm in the pseudocyst was suspected. Abdominal CAT showed that the pseudocyst had increased in size to $11 \times 15 \mathrm{~cm}$. Indeed, a pseudoaneurysm of the arteria gastrica sinistra was identified and was successfully occluded by selective embolization (Figs. 1 and 2).

Three weeks later abdominal CAT was repeated. There appeared to be a connection between the pseudocyst and the stomach (Fig. 3). This finding was confirmed by upper gastrointestinal endoscopy, which showed an opening approximately $3 \times 4 \mathrm{~cm}$ in size in the fundus of the stomach that communicated with the interior of the 


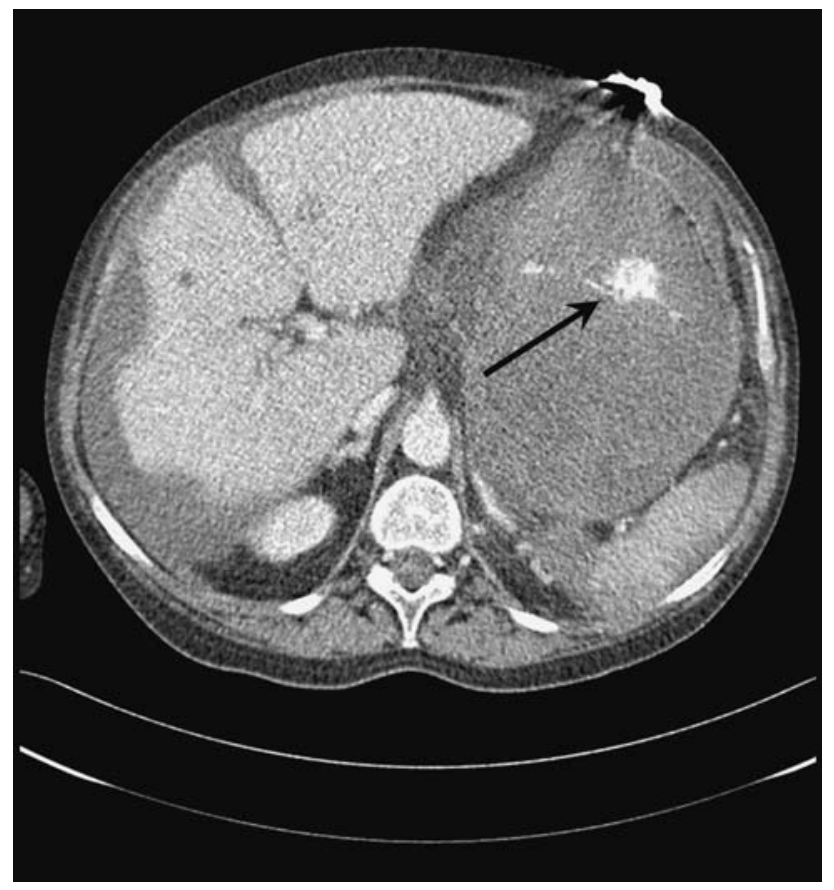

Fig. 1 CAT scan showing bleeding from the arteria gastrica sinistra (black arrow)

pseudocyst. Because there appeared to be adequate drainage of the cyst into the stomach, no further therapeutic steps were undertaken. Several days later the patient was discharged in good condition. Subsequent follow-up endoscopies showed a gradual healing of the opening and fistulous tract. The patient recovered uneventfully, and no recurrence of the pseudocyst was seen on ultrasonographic examination at 24-month follow-up.

\section{Discussion}

Pseudoaneurysmal bleeding and rupture are potential lifethreatening complications of pancreatic pseudocysts. Pseudoaneurysms result from autodigestion and weakening of the wall of the pseudocyst and an adjacent artery by activated proteolytic enzymes or severe inflammation. Reported mortality rates, which vary between $15 \%$ and $43 \%$, are high if a bleeding occurs [10, 11]. Fortunately, nowadays much acute bleeding from pseudoaneurysms can be effectively managed by selective angioembolization [12]. Pseudocyst rupture into the abdominal cavity leads to severe peritonitis. However, in case of "spontaneous" rupture into the gastrointestinal tract, as occurred in our patient, there is instant relief of complaints, including pain, feeling of fullness, or intestinal obstruction. Complete cyst resolution may follow without need for further therapeutic intervention. We hypothesize that in this patient, "spontaneous" breakthrough was facilitated by postembolization
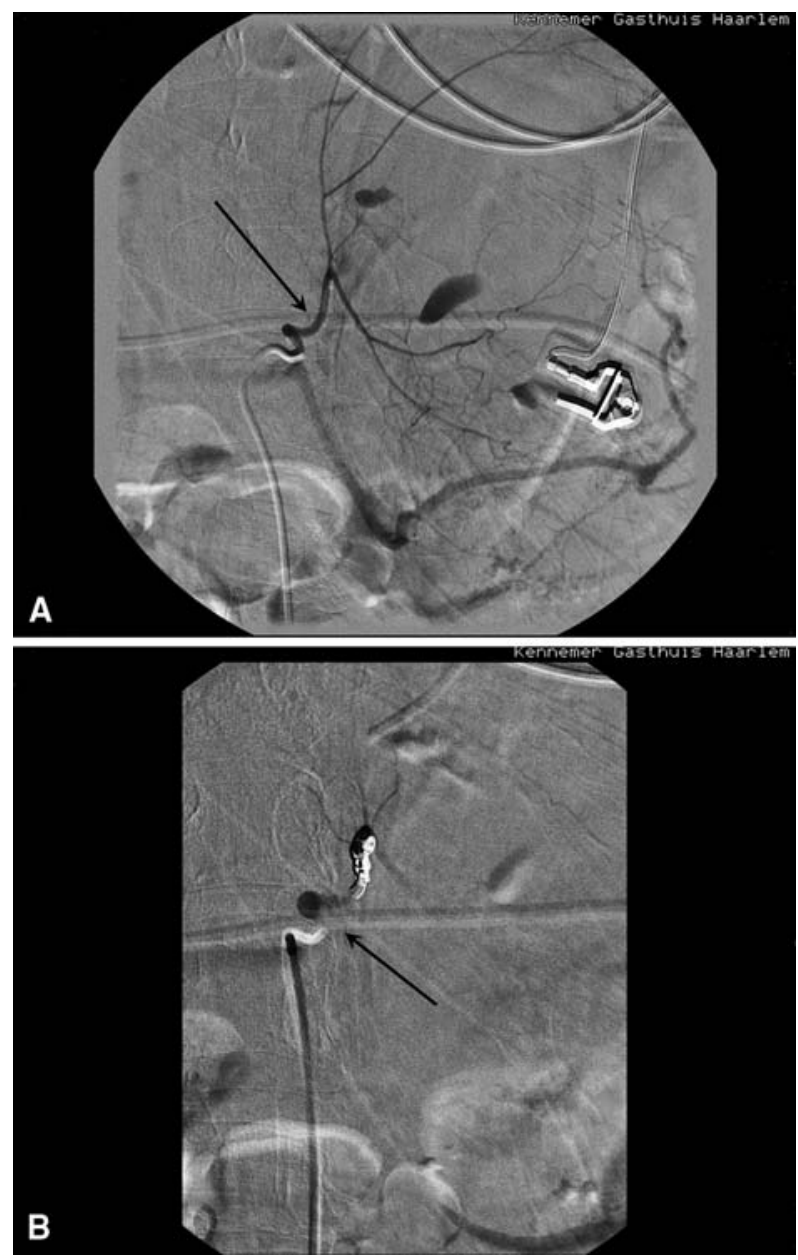

Fig. 2 Angiography of the arteria gastrica sinistra (black arrow). (A) Extravasation. (B) Successful selective embolization of the arteria gastrica sinistra

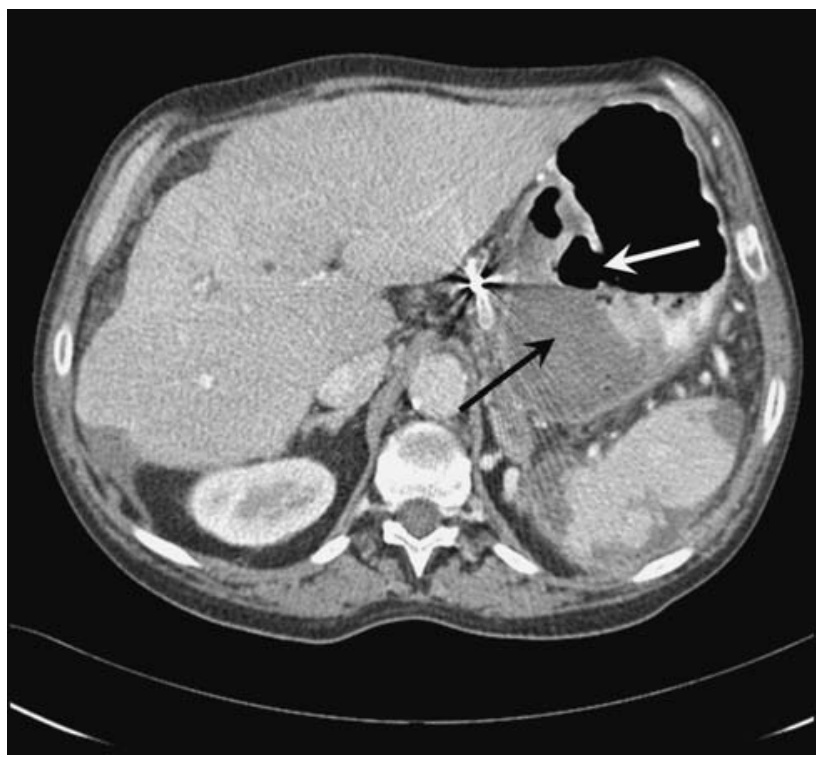

Fig. 3 CAT scan showing a connection (white arrow) between the stomach and the pancreatic pseudocyst (black arrow) 
ischemia of the gastric wall in combination with mechanical pressure of the bulging pseudocyst.

Open Access This article is distributed under the terms of the Creative Commons Attribution Noncommercial License which permits any noncommercial use, distribution, and reproduction in any medium, provided the original author(s) and source are credited.

\section{References}

1. Baillie J (2004) Pancreatic pseudocysts (part I). Gastrointest Endosc 59:873-879

2. Byrne MF, Mitchell RM, Baillie J (2002) Pancreatic pseudocysts. Curr Treat Options Gastroenterol 5:331-338

3. Rosso E, Alexakis N, Ghaneh P et al (2003) Pancreatic pseudocyst in chronic pancreatitis: endoscopic and surgical treatment. Dig Surg 20:397-406

4. Andren-Sandberg A, Dervenis C (2004) Pancreatic pseudocysts in the 21st century. Part II: natural history. JOP 5:64-70
5. Ali J, Greenberg H (1992) Spontaneous gastric decompression of pancreatic pseudocyst. Can J Surg 35:104-106

6. Hanna WA (1960) Rupture of pancreatic cysts. Report of a case and review of the literature. Br J Surg 47:495-498

7. Levy I, Ariche A (1999) Complete recovery after spontaneous drainage of pancreatic abscess into the stomach. Scand J Gastroenterol 34:939-941

8. Milz J, Jakobs R, Riemann JF (1996) Spontaneous internal drainage of a pancreatic pseudocyst: a case report. Hepatogastroenterology 43:282-286

9. Yeom HJ, Yi SY (2007) Spontaneous resolution of pancreatic gastric fistula. Dig Dis Sci 52:561-564

10. de Perrot M, Berney T, Buhler L et al (1999) Management of bleeding pseudoaneurysms in patients with pancreatitis. Br J Surg 86:29-32

11. Mallick IH, Winslet MC (2004) Vascular complications of pancreatitis. JOP 5:328-337

12. Mansueto G, Cenzi D, D’Onofrio M et al (2007) Endovascular treatment of arterial bleeding in patients with pancreatitis. Pancreatology 4:360-369 